\title{
Fracture Energy of Engineered Cementitious Composites ${ }^{\dagger}$
}

\author{
Anamaria Cătălina Mircea ${ }^{1, *}$ and Tudor Panfil Toader ${ }^{1,2}$ \\ 1 Faculty of Civil Engineering, Technical University of Cluj-Napoca, 15 Constantin Daicoviciu Street, \\ 400020 Cluj-Napoca, Romania; tudor.toader@incerc-cluj.ro \\ 2 NIRD URBAN-INCERC Cluj-Napoca Branch, 117 CaleaFlorești, 400524 Cluj-Napoca, Romania \\ * Correspondence: anamaria_catalina_mircea@yahoo.com \\ + Presented at the 14th International Conference on Interdisciplinarity in Engineering-INTER-ENG 2020, \\ Târgu Mureș, Romania, 8-9 October 2020.
}

Published: 10 December 2020

\begin{abstract}
The aim of this paper is to present preliminary results regarding Engineered Cementitious Composites (ECC) and their behavior when experimentally assessing their fracture energy, by measuring the flexural tensile strength (limit of proportionality, residual). As a characteristic of a ductile material, fracture energy is an important parameter when assessing ECC post-cracking residual stresses. With $2 \%$ fibers addition in the mixtures, the crack width can be controlled and the material's ability to bear a tensile strain-hardening capacity has been assessed. Ninety days flexural tensile strength tests were performed in order to obtain preliminary results on ECC prismatic specimens.
\end{abstract}

Keywords: fracture energy; engineered cementitious composites; limit of proportionality; residual strength; fly ash

\section{Introduction}

Using 2\% of fibers well distributed, Engineered Cementitious Composites (ECC), with the ability to undergo the tensile strain-hardening capacity with over 300 times that of normal concrete, allow cracks to form and control the crack width [1]. Those materials with high ductility and damage tolerance under tensile and shear loadings [1,2] have a distinguished design compared to Fiber Reinforced Concrete (FRC) based on micromechanics of first crack initiation, fiber bridging and steady-state flat-crack propagation mode [3].

Kanda and Li, in 1998 [4], established two conditions of Engineered Cementitious Composites in order to achieve the strain-hardening behavior and to induce the multiple cracking behavior. The first condition is defined by the first crack stress as a strength criterion and the second one is the steady-state cracking defined as energy criterion. Responsible for initiating the micro cracks, the strength criterion ensures the tensile load that allows the micro cracks to be less than the maximum capacity of the fiber fringing. The energy criterion that prescribes switching the Griffith-type crack is the second condition. As the crack length extends, the opening of the crack increases as for FRC to steady-state flat-crack propagation mode in the case of tension-softening behavior [3].

The fracture energy is the amount of energy that is necessary to generate a crack of one unit of area. For concrete, the fracture energy can be determined experimentally by applying flexural tensile strength loading on a notched concrete specimen [5] and can be calculated as the area under the load-deflection curve divided with the net cross section of the specimen situated above the notch. It is shown that the method of determining the fracture energy by means of stable three-point bend tests on notched beams seems suitable for concrete and similar materials [6]. In order to generate the area under the load-deflection curve, the first step is to experimentally evaluate the flexural tensile strength of the concrete by means of Limit of Proportionality (LOP) and residual strength. 
The importance in studying fracture energy is to determine the formation of multiple cracks in the material in order to achieve high tensile ductility similar to ductile materials.

According to Mehta and Monteiro [5], the fracture energy increases when the aggregate size increases, among other factors. Delivering dimensional stability and wear resistance, aggregates can also affect negatively the tensile performances due to the increasing of the tortuosity of the fracture path, which leads to a tough Engineered Cementitious Composites matrix [3]. The propagation of the cracks after they occur leads dramatically to the damage of the steady-state flat-crack propagation process in Engineered Cementitious Composites and the sacrifice of the multiple-cracking behavior [7]. Therefore, in order to generate this effect, fine aggregates should be used in the mix-design, such as micro-silica sand with maximum grain size of $250 \mu \mathrm{m}$ and a mean size of $110 \mu \mathrm{m}$ instead of coarse aggregates.

To reduce the environmental impact [8-11], fly ash considered pozzolans and by-product materials and are added to concrete as a cement replacement for economic reasons and to improve the workability of the material as well as prevent their waste disposal. Studies have shown that industrial by-products can be successfully used as partially replacing OPC in concrete, but also as raw material by their chemical activation in the production of new, innovative materials [12,13].

To obtain the residual strength curve, the relationship between the fracture strength and the crack length are needed. The residual strength depends on the crack size. For the structures where the cracks grow slow like monolithic and single load paths, the residual strength capability is simple. For build-up structures, multiple load paths and fail-safe structures where the crack grow slow, due to the geometric construction of the components, the residual strength analysis is complicated. The residual strength for a given structure is a function of the service time.

The main objective of the current research is to explore the development of ECC materials and analyze their mechanical properties, as well as to explore initial experimental methods and testing procedures in order to assess the fracture energy (by means of flexural tensile strength) and the potential approach regarding concrete delay of cracks growing when the material present defects under certain loads, in accordance with fracture mechanics.

\section{Experimental Program}

Engineered Cementitious Composite mixtures presented in this study were developed based on available literature [14] and starting from a rigorous selection of materials that will be used. The initiation of fracture at pre-existing cracks is affected by the residual stresses in structural materials and can modify the intensity of the crack tip stress field [15]. Depending on the crack opening or crack closure, residual stress can promote or inhibit the initiation of fracture. Residual stress affects the fracture initiation behavior of the materials and their resistance to subsequent crack growth [16]. These parameters can be affected by the raw materials and their specific mix-design ratio.

\subsection{Raw Materials and Mix-Design Ratios}

In order to produce the ECC samples, Portland cement CEM I 42.5R, Class F fly ash from a local source, silica-sand (maximum size of $0.3 \mathrm{~mm}$ ) and river sand (maximum size $4 \mathrm{~mm}$ ), polyvinyl alcohol fibers (PVA), limestone slurry and a water reducing superplasticizer admixture were used. The characteristics of the PVA fibers used have the length of $8 \mathrm{~mm}$, are chemical resistant, have UV-stability, are hydrophilic and previous studies have shown that they meet the requirements of strain-hardening performance of the Engineered Cementitious Composites [14]. The limestone slurry paste was obtained from a local source and, since water is an important parameter that influences the fresh and hardened state of concrete, the water content was measured $(19.7 \%)$.

Two types of sand were used in the production of the samples in order to study the influence of this material. One mixture was produced using silica-sand (T1E) and one mixture was produced using normal river sand (T2E).

The mix-design ratio was developed based on ECC developed mixtures used in the literature (Table 1) [14] and are presented in Table 2. 
Table 1. Engineered Cementitious Composites (ECC) base mix-design [14].

\begin{tabular}{cccccccc}
\hline Mixtures & CEM $^{2}$ & FA $^{3}$ & Sand & Water & PVA & LS $^{4}$ & Admixture \\
\hline SS-L-PVA- FA/C & 1.00 & 1.20 & 0.76 & 0.65 & 0.05 & 0.18 & 0.02 \\
\hline values reported to cement quantity, ${ }^{2}$ & CEM—cement; ${ }^{3}$ FA—fly-ash, ${ }^{4}$ LS-limestone slurry.
\end{tabular}

Table 2. Engineered Cementitious Composites mixture proportions.

\begin{tabular}{ccccccccc}
\hline \multirow{2}{*}{ Mixture } & \multirow{2}{*}{ Type of Sand } & \multicolumn{7}{c}{ Ingredients (wt.\%) } \\
\cline { 3 - 9 } & Silica Sand & $\mathbf{C E M}^{\mathbf{2}}$ & FA $^{3}$ & Sand & Water & PVA & LS $^{\mathbf{4}}$ & Admixture \\
\hline \multirow{2}{*}{ T1E } & 1.00 & 1.20 & 0.76 & 0.58 & 0.05 & 0.22 & 0.02 \\
\hline \multirow{2}{*}{ T2E } & Normal Sand & 1.00 & 1.20 & 0.76 & 0.56 & 0.05 & 0.22 & 0.02 \\
\hline \multicolumn{7}{r}{ values reported to cement quantity, ${ }^{2}$ CEM-cement; ${ }^{3}$ FA—fly-ash, ${ }^{4}$ LS-limestone slurry. }
\end{tabular}

\subsection{Testing Methods}

The mechanical properties (flexural and compressive strength) of the ECC samples were determined using $40 \times 40 \times 160 \mathrm{~mm}$ prismatic specimens for each of the proposed mixtures; the mean value of the results was considered relevant for the data interpretation. The testing method was in accordance to EN 196-1 [17] and the samples were tested at 28 and 90 days, under laboratory conditions $\left((20 \pm 2){ }^{\circ} \mathrm{C}\right.$ and $\left.(50 \pm 3) \% \mathrm{RH}\right)$.

In order to investigate the 90 days flexural tensile strength (LOP and residual strength) of the mixtures, $150 \times 150 \times 600 \mathrm{~mm}$ samples were produced in the same conditions. The tensile behavior of the samples is evaluated in terms of the residual tensile strength values when subjected to bending, determined by the load-displacement curve of the crack edge, obtained by applying a point load centered on a notched prism. The loading scheme for the test is presented in Figure 1.

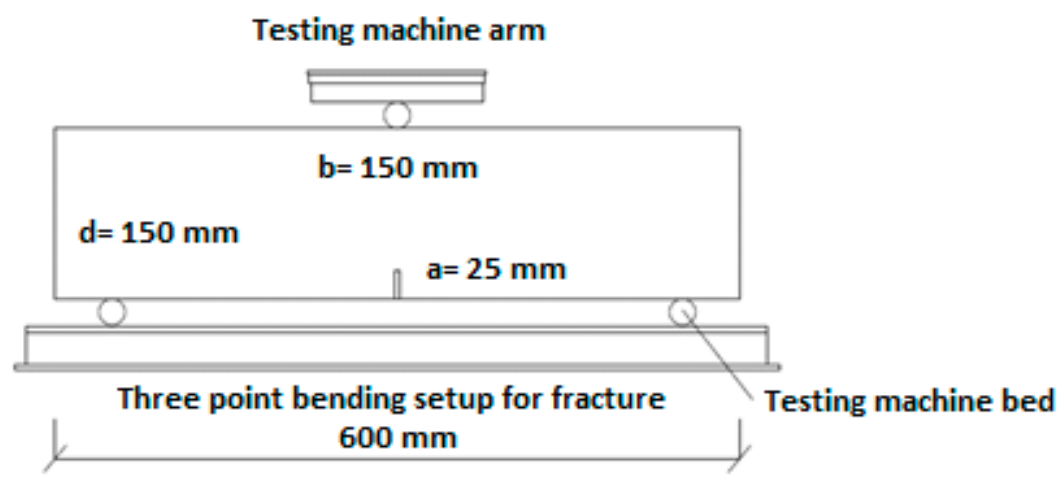

Figure 1. ECC flexural tensile strength loading scheme.

Tests to determine the stress displacement (CMOD) diagram, and to determine the values obtained for the displacements of 0.5, 1.5, 2.5 and $3.5 \mathrm{~mm}$, were carried out according to SR EN 14,651 + A1 [18]. The Limit of Proportionality (LOP) was determined according to Equation (1) and the residual strength was determined according to Equation (2) [17].

$$
\mathrm{f}_{\mathrm{ct}, \mathrm{L}}^{\mathrm{f}}=\left(3 \mathrm{~F}_{\mathrm{L}} \mathrm{l}\right) /\left(2 \mathrm{bh}_{\mathrm{sp}}{ }^{2}\right)\left(\mathrm{N} / \mathrm{mm}^{2}\right)
$$

where, $\mathrm{f}_{c t, L}$ is the Limit of Proportionality; $F_{L}$ is the corresponding stress; 1 is the length between the rollers; $b$ is the width of the sample and $h_{s p}$ is the distance between the lower part of the notch and the upper part of the sample.

$$
\mathrm{f}_{\mathrm{Rj}}=\left(3 \mathrm{~F}_{\mathrm{j}} \mathrm{l}\right) /\left(2 \mathrm{bh}_{\mathrm{sp}}{ }^{2}\right)\left(\mathrm{N} / \mathrm{mm}^{2}\right)
$$


where, $f_{R j}$ is the residual resistance, which corresponds to $\mathrm{CMOD}_{j}(j=1,2,3,4) ; F_{j}$ is the corresponding stress, which corresponds to $\mathrm{CMOD}_{j}(\mathrm{j}=1,2,3,4) ; 1$ is the length between the rollers; $b$ is the width of the sample and $h_{s p}$ is the distance between the lower part of the notch and the upper part of the sample. In Figure 2, the specimens equipped, ready to be tested, are presented.

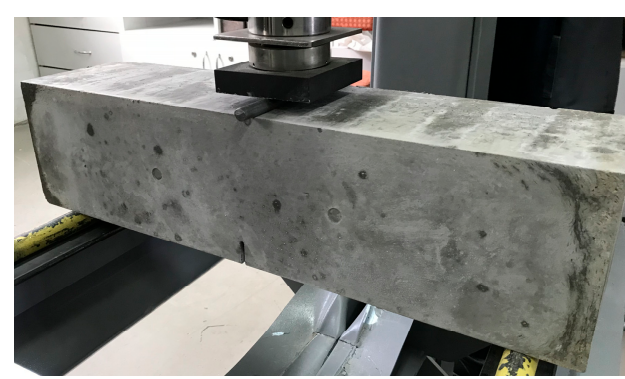

(a)

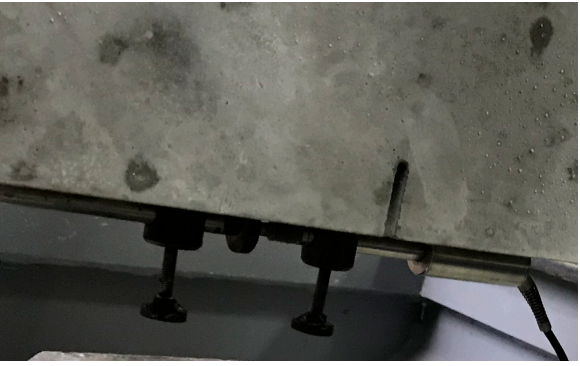

(b)

Figure 2. Flexural tensile strength: (a) loading scheme of the samples; (b) transducer used for the displacement measurement.

\section{Results and Discussions}

\subsection{Mechanical Properties}

The flexural and compressive strength test results of Engineered Cementitious Composites mixtures with different types of sand are presented in Figures 3 and 4.

\section{Flexural strength (MPa)}

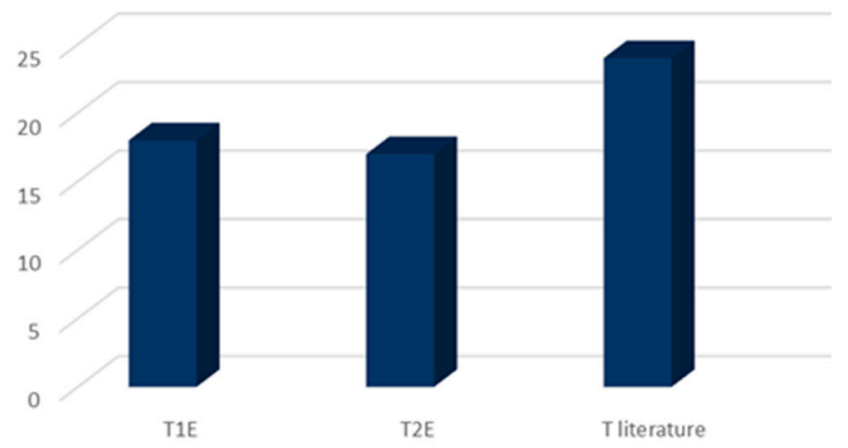

Figure 3. Flexural strength of ECC mixtures at 90 days.

Compressive strength ( $\mathrm{MPa}$ )

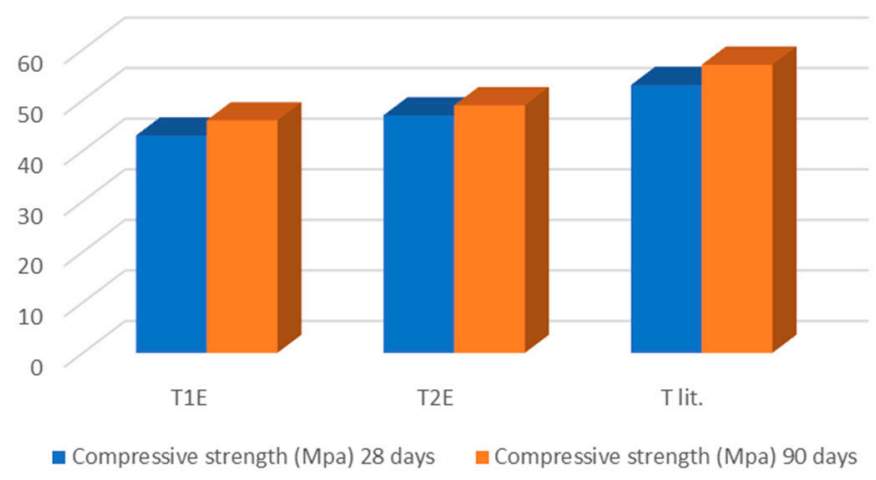

Figure 4. Compressive strength of ECC mixtures at 28 and 90 days. 


\subsection{Flexural Tensile Strength (LOP and Residual Strength)}

Three point bending tests (3PB) performed at 90 days on the $150 \times 150 \times 600 \mathrm{~mm}$ samples and experimental results and curves concerning the nominal stress and Crack Mouth Opening Displacement (CMOD) are depicted in Figures 5 and 6. Results regarding the LOP are presented in Table 3 and results regarding the residual strength are presented in Table 4 . The mean of the individual specimens' curves is also depicted.

Based on the graph curves above, the residual strengths $f_{R, j}$ (evaluated at four different CMOD values), and the flexural tensile strength (LOP) $\mathrm{f}_{\mathrm{ct}, \mathrm{L}}^{\mathrm{L}}$ were presented for both of the ECC mixtures proposed. It can be noticed that the post-cracking flexural behavior of samples is generally exhibiting the desirable high residual strength and toughness performance. T2E samples show a much higher post-cracking flexural behavior than T1E samples. A constant CMOD loading rate was maintained until the end of the test. The end point of the test is at $3.5 \mathrm{~mm}$ and that is the point where the fracture energy should be calculated.

To find the fracture energy of the specimens, the areas under the curves need to be calculated based on mathematical formulas that are dependent on the geometrical characteristics of the samples [19].

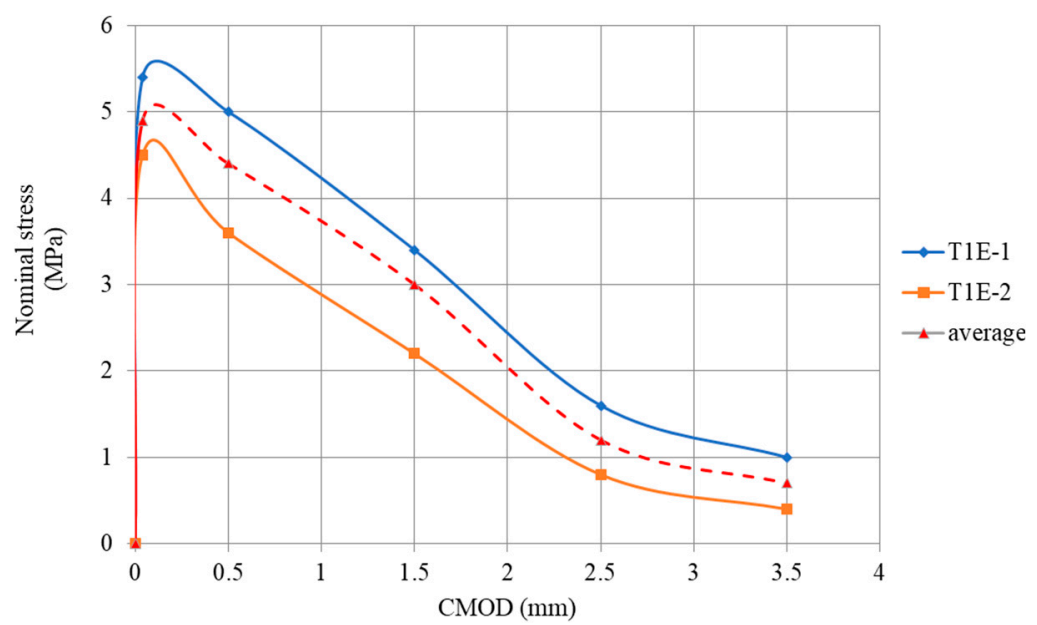

Figure 5. Flexural tensile strength (limit of proportionality, residual)—T1E (90 days).

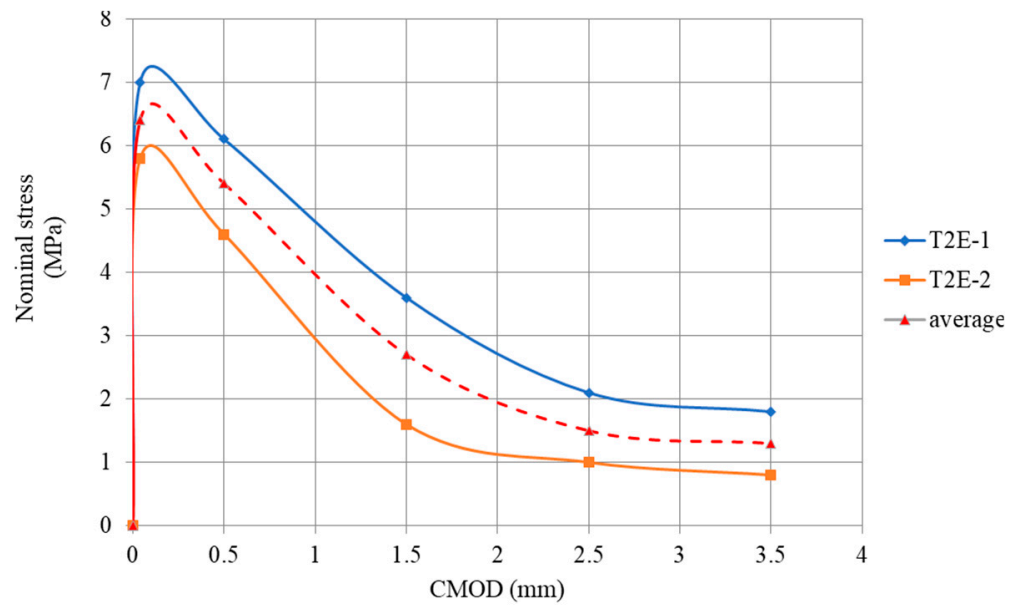

Figure 6. Flexural tensile strength (LOP, residual)_-T2E (90 days). 
Table 3. ECC mixtures Limit of Proportionality.

\begin{tabular}{|c|c|c|c|c|c|c|c|}
\hline & & $F_{L}$ & 1 & b & $\mathbf{h}_{\mathrm{ps}}$ & $\mathrm{f}_{\mathrm{fct}, \mathrm{L}}$ & $\mathbf{f}_{\mathrm{fct}, \text { Lmed }}$ \\
\hline \multirow{2}{*}{ T1E } & T1E-1 & 16844 & \multirow{4}{*}{500} & \multirow{4}{*}{150} & \multirow{4}{*}{125} & 5.4 & \multirow{2}{*}{4.9} \\
\hline & T1E-2 & 14018 & & & & 4.5 & \\
\hline \multirow{2}{*}{$\mathrm{T} 2 \mathrm{E}$} & T2E-1 & 21832 & & & & 7.0 & \multirow{2}{*}{6.4} \\
\hline & T2E-2 & 18073 & & & & 5.8 & \\
\hline
\end{tabular}

Table 4. ECC residual strength.

\begin{tabular}{|c|c|c|c|}
\hline \multicolumn{2}{|c|}{ Mixture ID } & $\begin{array}{c}\text { CMOD } \\
(\mathrm{mm})\end{array}$ & $\begin{array}{c}\mathbf{f}_{\mathrm{R}, \mathrm{j}} \\
(\mathrm{MPa})\end{array}$ \\
\hline \multirow{8}{*}{ T1E } & \multirow{4}{*}{ T1E-1 } & 0.5 & 5.2 \\
\hline & & 1.5 & 3.8 \\
\hline & & 2.5 & 1.6 \\
\hline & & 3.5 & 1.0 \\
\hline & \multirow{4}{*}{ T1E-2 } & 0.5 & 3.6 \\
\hline & & 1.5 & 2.2 \\
\hline & & 2.5 & 0.8 \\
\hline & & 3.5 & 0.4 \\
\hline \multirow{8}{*}{$\mathrm{T} 2 \mathrm{E}$} & \multirow{4}{*}{ T2E-1 } & 0.5 & 6.1 \\
\hline & & 1.5 & 3.6 \\
\hline & & 2.5 & 2.1 \\
\hline & & 3.5 & 1.8 \\
\hline & \multirow{4}{*}{ T2E-2 } & 0.5 & 4.6 \\
\hline & & 1.5 & 1.7 \\
\hline & & 2.5 & 1.0 \\
\hline & & 3.5 & 0.8 \\
\hline
\end{tabular}

\section{Conclusions}

In the present paper, an experimental study was presented aiming at evaluating the cracking behavior in terms of flexural tensile strength of ECC samples produces using local raw materials.

Comparing the test results for compressive and flexural strength with the results obtained in the literature, it was noticed that the mixtures from the literature have a higher compressive strength: $53 \mathrm{MPa}$ at 28 days compared to $45 \mathrm{MPa}$ for the mixtures from this paper, and for flexural strength, $24 \mathrm{MPa}$ at 28 days compared to $18 \mathrm{MPa}$ for the mixtures from this paper.

Post-cracking flexural behavior of the tested samples was generally exhibiting the desirable high residual strength and toughness performance expected for the mix-design of ECC mixtures.

As the fracture energy is tightly bound with the obtained results regarding the flexural tensile strength (LOP, residual) and it can be obtained based on mathematical formulas, further studies will be carried on regarding the output of the presented results in terms of fracture energy and evaluating the parameters that affect this characteristic.

Author Contributions: Conceptualization, A.C.M. and T.P.T.; methodology, A.C.M. and T.P.T.; validation, A.C.M.; formal analysis, A.C.M. and T.P.T.; investigation, A.C.M..; data curation, A.C.M.; writing-original draft preparation, A.C.M.; writing-review and editing, A.C.M. and T.P.T.; visualization, A.C.M.; supervision, A.C.M. All authors have read and agreed to the published version of the manuscript.

Funding: This research received no external funding.

Conflicts of Interest: The authors declare no conflict of interest. 


\section{References}

1. Li, V.C. On Engineered Cementitious Composites (ECC) A Review of the Material and Its Applications. J. Adv. Concr. Technol. 2003, 1, 215-230. [CrossRef]

2. Li, V.C. Engineered Cementitious Composites (ECC)-Tailored Composites through Micromechanical Modeling Volume 2164. CSCE 1997, 1-38.

3. Sherir, M.A.A.; Houssain, K.M.A. Fracture Energy Characteristics of Engineered Cementitious Composites Incorporating Different Aggregates. 2014, 2982, 293-302.

4. Kanda, T.; Li, V.C. Multiple Cracking Sequence and Saturation in Fiber Reinforced Cementitious Composites. Concr. Res. Technol. 1998, 9, 19-33. [CrossRef]

5. Mehta, P.K.; Monteiro, P.J.M. Concrete: Microstructural Properties and Materials, 3rd ed.; McGraw Hill: New York, NY, USA, 2006.

6. Petersson, P.E. Fracture Energy of Concrete: Method of Determination. Cem. Concr. Res. 1980, 10, 78-89. [CrossRef]

7. Sahmaran, M.; Lachemi, M.; Hossain, K.M.A.; Ranade, R.; Li, V. Influence of Aggregate Type and Size on Ductility and Mechanical Properties of Engineered Cementitious Composites. ACI Mater. J. 2009, 106, 308-316.

8. Mehta, P.K. Influence of Fly Ash Characteristics on The Strength of Portland-Fly Ash Mixtures. Cem. Concr. Res. 1985, 15, 669-674. [CrossRef]

9. Mindess, S.; Young, J.F.; Darwin, D. Concrete, 2nd ed.; Pearson Education, Inc.: Upper Saddler River, NJ, USA, 2003.

10. Li, V.; Wu, C.; Wang, S.X.; Ogawa, A.; Saito, T. Interface Tailoring for Strain-Hardening PVA-ECC. ACI Mater. J. 2002, 99, 463-472.

11. Rus, M.-I. The knowledge triangle in a knowledge-based society. Univ. Oradea. Şt. Ec Tom XXII 2013, 1, 942-947.

12. Szilagyi, H.; Baeră, C.; Hegyi, A.; Lăzărescu, A. Romanian resources of waste and industrial by-products as additions for cementitious mixtures. Int. Multidiscip. Sci. Geoconf. SGEM 2018, 18, 325-332.

13. Lăzărescu, A.; Mircea, C.; Szilagyi, H.; Baeră, C. Mechanical properties of alkali activated geopolymer paste using different Romanian fly ash sources-Experimental results. MATEC Web Conf. 2019, 289, 11001. [CrossRef]

14. Mircea, A.C.; Mircea, C.; Szilágyi, H.; Baeră, C.; Hegyi, A. Experimental study regarding the influence of fibre to matrix compatibility on general performance of Fibre Engineered Cementitious Materials (FECM). MATEC Web Conf. 2019, 289, 04005. [CrossRef]

15. Withers, P.J. Residual stress and its role in failure. Rep. Prog. Phys. 2007, 70, 2211-2264. [CrossRef]

16. Coules, H.E.; Horne, G.C.M.; Abburi Venkata, K.; Pirling, T. The effects of residual stress on elastic-plastic fracture propagation and stability. Mat. Des. 2018, 143, 131-140. [CrossRef]

17. ASRO. SR EN 196-1. Methods of Testing Cement. Determination of Strength; Romanian Standards Association: Bucharest, Romania, 2016.

18. ASRO. SR EN 14651+ A1. Method of Testing a Concrete with Metal Fibers. Measurement of Bending Tensile Strength (Proportionality Limit (LOP), Residual Strength); Romanian Standards Association: Bucharest, Romania, 2008.

19. Wang, S.; Li, V.C. Engineered Cementitious Composites with High-Volume Fly Ash. ACI Mater. J. 2007, 104, 233-241.

(C) 2020 by the authors. Licensee MDPI, Basel, Switzerland. This article is an open access article distributed under the terms and conditions of the Creative Commons Attribution (CC BY) license (http://creativecommons.org/licenses/by/4.0/). 